
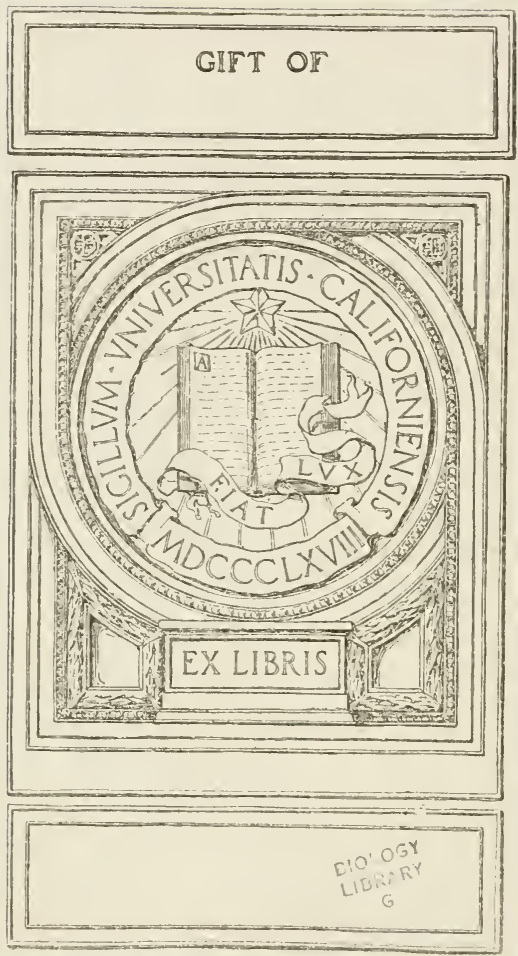


\section{TIME REQUIRED TO FREE PASTU RES}

FROM TICKS BY STARIATION.

Date of removal of all animals from pasture.

July 1

August 1

September 1

October 1 to November 1, inclusive.

December 1

December 15 to March 15, inclusive. April 1

April 15

May 1
Date when pasture will be FREE lROSOI ticks.

llarch 1

Iay I

July 1

August 1

lugust 15

September 1

september 15

Oclober 15

November 1 


\title{
HOW TO GET THE LAST TICK
}

\begin{abstract}
OBSERVATIONS RESULTING FROM ACTIVE FIELD EXPERIENCE IN TICK ERADICATION
\end{abstract}

By

IV. M. MacKELLAR
Tick Eradication Division

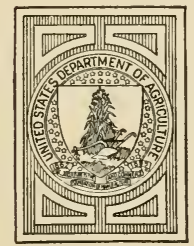

BUREAU OF ANIMAL INDUSTRY

U. S. DEPAR'TIENT OF AGRICULTURE

WASIINGTON, D. C. 
Digitized by the Internet Archive in 2008 with funding from Microsoft Corporation

\section{Gift}




\section{HOW TO GET THE LAST TICK.}

\section{INTRODUCTION.}

During the past 15 years results obtained in eradicating cattle ticks from the infested areas of the United States have clearly established the fact that it is possible and practicable to eliminate this pest permanently from any section of the country. This is true whether the infested cattle are under fence or on open range, or whether the infested locality is rough, swampy, wooded, or otherwise. The large area that has been freed and remains tick-free is positive proof of the value of this work which, more than any other factor, is making possible the establishment of a growing and profitable cattle industry in the South.

Notwithstanding the fact that all necessary information regarding the cattle tick (Margaropus annulatus), the disease which it transmits, and a positive method for its complete eradication are, and for years past have been, available, tick eradication continues to present many problems which vary with the locality in which the work is being conducted. In fact, in its last analysis, it is a community problem and therefore is, and always must be, a work of the

Nоте.-The author of this circular was assigned in 1906 to the duties of inspector in charge of tick eradication in the State of California. On final completion of the work in that State in 1916, including an area of nearly 80,000 square miles, he was transferred to the same duties in the State of Georgia. In the five years following, up to the time of his transfer back to California at his own request, he cooperated successfully with the Georgia State officials and succeeded in practically eliminating cattle ticks from approximately 80 Georgia counties. 
people in which success or failure depends largely on the degree of support and cooperation given. However, in tick eradication, as in all other undertakings, a leader is essential to plan and direct the campaign, and as the leadership in the fight to eliminate the tick is usually taken by the inspector, the purpose of this circular is to emphasize a few of the fundamental facts, a knowledge of which is essential, and to outline a working plan that will assist him in carrying out the details of this work.

\section{LIFE HISTORY OF THE TICK IMPORTANT.}

To employ intelligently and successfully methods of eradicating the cattle tick, it is of first importance to know the life history of this tick, as it is on the life cycle, which never changes, that all plans of extermination are based. The usual host (animal infested) for this tick is cattle; and while several other kinds or species of ticks are found on cattle in the Southern States, it is the one most frequently found and hy far the most numerous.

The cattle tick is often confused with the other species of ticks occasionally found on cattle, and every inspector engaged in tick eradication should learn to identify and distinguish the eattle tick from the harmless varieties. With a little study, and by comparing the various kinds, particularly adult females, it is not a difficult matter to differentiate between the ticks that may be found on cattle. United States Department of Agriculture Farmers' Bulletin No. 569, "Texas or 'Tick Fever," describes and illustrates the ticks found on eattle, and will be of great assistance to those who wish to become familiar with the sulject. Horses and mules are sometimes infested with this tick, and when they are permitted to range on tick- 

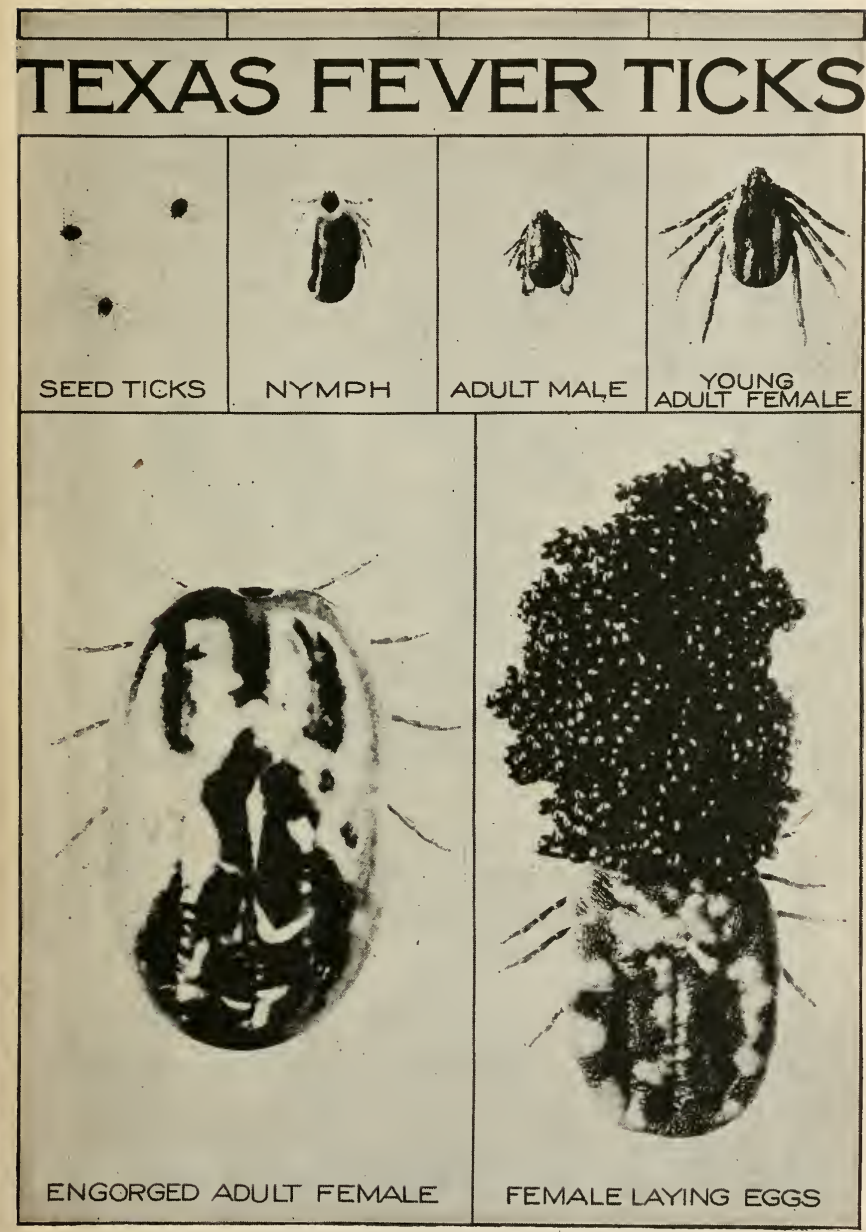

ENGORGED ADULT FEMALE

FEMALE LAYING EGGS

FIG. 1.-Texas-fever ticks at various stages of development. (Mragnified 5 times.) 
infested pastures they must he given the same consideration as cattle.

In describing the life history of this tick it is customary to start at the point where the fully dereloped and fertilized female, engorged with blood, loosens her hold on the skin of the cow and drops to the ground, where she at once searches for a hiding place under grass, leaves, or other litter affording protection from the direct rays of the sun. She begins laying her eggs in from 2 days to 3 weeks later, in spring, summer, or fall, while during the winter months this process may be delayed anywhere from 2 weeks to 3 months. The eggs are voided from an opening on the underside of the body, just back of the head, and appear in a gradually growing, grapelike cluster, and may be from a few hundred to as many as 5,000, 95 per cent of which will hatch under favorable conditions. Egg laying may be completed in 4 days in summer, or may be prolonged as much as 5 months during winter. When laying is finished, the mother tick is small and shriveled, and soon dies.

The eggs are very small, oval-shitped, and brownish in color, and as laid they are coated with a sticky secretion which causes them to adhere in clusters and no doubt keeps them from drying. In from 19 days in summer to 6 months during the fall and winter the eggs begin to hatch. The little brown, six-legged larva, or seed ticks, crawl from the eggs and soon ascend near-by vegetation, thereby increasing their chances of reaching a host-which is absolutely essential to their further development. Is soon as opportunity is offered they attach themselves to a passing or resting cow, or in exreptional eases to horses and mules. Failing to find a host, the seed 
tick will starve in from 2 to 8 months, depending on the season of the year. The seed tick takes no food and does not increase in size until reaching a host. It must have the blood of cattle (or horses and mules) for its development.

Soon after reaching a favorable host the seed tick attaches itself to the skin and begins to draw blood at once, increasing in size. In a few days the young tick changes from a brown color to white, and in from 5 to 12 days it sheds its skin, or molts, acquir-

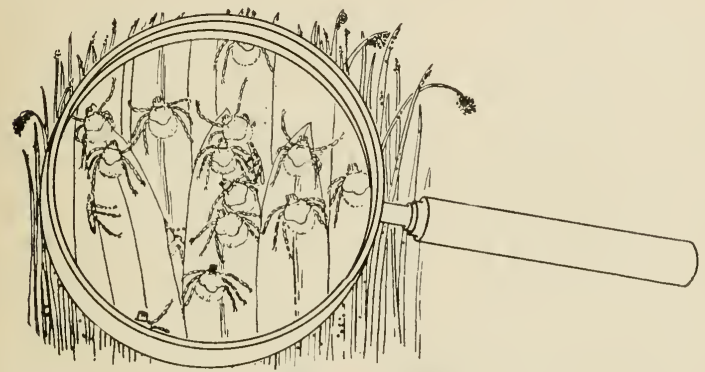

FIg. 2.-The little brown, six-legged larvæ, or seed ticks, crawl from the eggs and soon ascend near-by vegetation.

ing a fourth pair of legs, and is then known as a nymph.

In from 5 to 11 days after the first molt the tick again sheds its skin and becomes sexually mature. The male, measuring about one-tenth of an inch in length, is now fully developed and is seen as a small brown, oval tick of considerable activity. The female at the time of this molting is slightly larger than the male; she is not active, and seldom moves from her original point of attachment. After mating, the female develops rapidly and has been known to become fully engorged in 48 hours after the second molt, but usually from 4 days to a week are required. 
The time that elapses between the attachment of the tick as a seed tick and its dropping from the animal as a fully engorged female is generally about 3 weeks. The greatest length of time that a tick has been observed to stay on an animal is 66 days.

\section{METHODS OF ERADICATION.}

With an understanding of the life history and development of ticks, it is evident that they may be attacked in two locations, namely, on the pasture and on the cattle. Pastures may be rendered tickfree by excluding all cattle, horses, and mules until all ticks have died from starvation, or by the more common practice of permitting the cattle to remain on the infested pasture and disinfecting them at regular intervals in an arsenical bath, thus preventing the maturing of the tick on the cattle and reinfestation of the pasture. The seed ticks on the pasture, or those which hatch from eggs laid by females on the ground before dipping begins, will in time starve out, or, if they get upon the eattle, will be destroyed by the dipping.

This brings up the question of the time required to kill ticks by starvation, and the following table, which was prepared after careful investigation, is quoted from Farmers' Bulletin No. 498, "Extermination of the Texas-Fever Tick," United States Department of Agriculture, and may be depended upon as a reliable answer to this question: 
Time required to free pastures from ticks by stariation.

\begin{tabular}{|l|l|} 
Date of removal of all animals from pasture. & $\begin{array}{l}\text { Date when pasture } \\
\text { will be free from } \\
\text { ticks. }\end{array}$ \\
\hline July 1. & March 1. \\
August 1. & May 1. \\
September 1. & July 1. \\
October 1 to November 1 , inclusive. & August 1. \\
December 1. & August 15. \\
December 15 to March 15, inclusive. & September 1. \\
April 1. & September 15. \\
April 15. & October 15. \\
May 1 to June 15, inclusive. & November 1. \\
\hline
\end{tabular}

This table may also be used as an accurate guide to determine the length of time it is necessary to continue systematic dipping to insure complete eradication. It is evident that if all ticks are prevented by dipping from maturing and reinfesting a pasture, that pasture should be tick-free in the same length of time that it would take to starve out the ticks if all cattle, horses, and mules were excluded. In the application of this knowledge, where dipping is the means of preventing pasture reinfestation, it is, of course, necessary that careful inspection be made at the time of dipping to determine when mature ticks are last found on the cattle; the time dipping must continue is estimated from that date. In using this plan it has been the policy of the writer, with satisfactory results, as a margin of safety, to add 30 days to the starvation period. For example, mature ticks (not necessarily engorged) are last found on cattle being dipped on June 1-then those cattle should be dipped regularly at 14-day intervals until November 30 ; or if mature ticks are found July 1 , the eradication will not be completed until the following April 1 .

Systematic dipping in an arsenical solution is the method most generally followed in tick eradication. 
Occasionally, however, it is feasible to employ the "starvation" or "pasture-resting" methor in eliminating the tick from a pasture.

\section{"PASTURE RESTING."}

This is no dloubt one of the simplest methods of eradicating ticks when the local conditions are right for its proper use. To be successful it requires close attention to details and the thorough cooperation of the cattle owner. The pasture to be "rested" must be inclosed with good fences or natural barriers impassable for cattle, horses, or mules, and care must be taken to prevent these animals from getting into the pasture during the resting period. If, in inclosing a pasture for this purpose, it is necessary to build fences, these, as far as possible, should be made to traverse rough, inaccessible land where feed is short and where cattle will consequently have little tendency to stray directly up to the fences surrounding the resting area. When the pasture has been rested for the required length of time, determined by referring to the table "Time required to free pastures from ticks by starvation," it is ready to be stocked with tick-free cattle. The only precaution necessary to keep the area free is to see that all cattle, horses, or mules entering the premises are tick-free.

DIPPING.

Ticks upon cattle may be destroyed by the use of various agents, such as oils, arsenic, etc., which may be applied by hand, by the use of a spray pump, or by means of the dipping vat.' long experience

'For directions for const ructing a dipping vat, see larmers' Bulletin 1057 , "('attle-Fever Tieks." for metloxis of preparation of aroenicnl cattle dips, see Farmers' Bulletin No, bion. "Arsenical ('attle. l)i jus." 
having shown the dipping vat to be the cheapest and best method of treating animals for ticks, dipping in an arsenical solution at 14-day intervals is now the method of disinfection in nearly universal use in systematic tick eradication.

The work of dipping will be greatly facilitated by properly constructed vats and well-arranged pens and chutes, and the inspector should try to arrange these details before the season's dipping begins. The

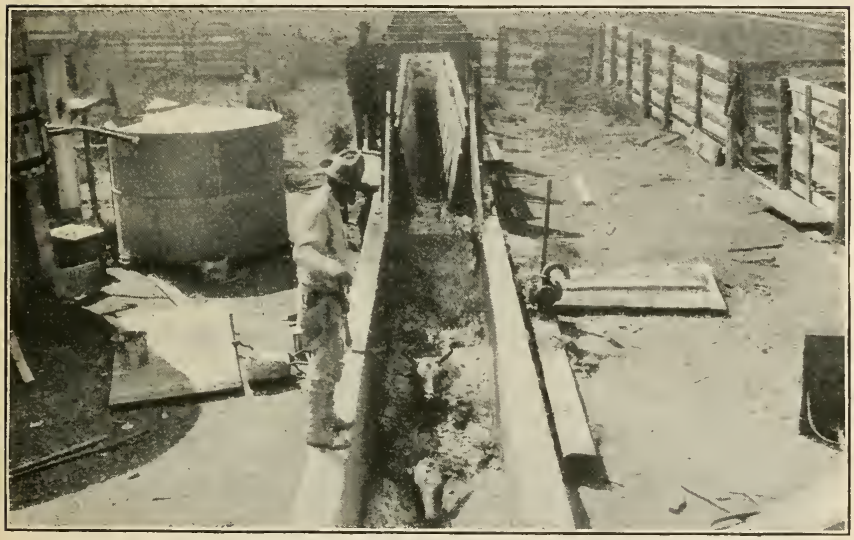

FIG. 3.-Long experience has shown the dipping vat to be the cheapest and best method of treating animals for ticks.

little extra expense required to put the dipping plant in good working order will be more than repaid by the ease with which the cattle can be handled and time saved in the operation.

Cattle dipping in an arsenical bath of proper strength in a well-constructed vat is a simple and safe treatment, which with reasonable care is accompanied by no risk or danger of injury to the treated animal. Accidents are usually due to carelessness and can be 
avoided in nearly all cases by the use of a little common sense. Before any cattle are dipped the solution in the vat must be thoroughly stirred, tested, and brought to proper strength. All cattle should be waterel not more than 4 or 5 hours prior to dipping. Cattle should not be dipped when they are hot, and after dipping they should be allowed to return to their home range at their leisure. After dipping they should be held in the dripping pen until the excess dip stops dripping from their bodies. The inspector should insist that cattle be handled carefully and humanely at dipping vats. The best time to dip -is in the cool of the early morning, with the exception that in some cases it is advisable to dip work oxen Saturday afternoon so that they may rest the following Sunday.

The virtue of arsenic as a tick-destroying agent lies in its poisonous properties. The fact that it is a violent poison to man and animals should never be forgotten. White arsenic, concentrated solutions, and proprietary dips must be kept in tight containers inaccessible to animals and children, preferably in a locked room used only for their storage. If, by accident, concentrated solution or proprietary dip gets on the skin or clothing it should be removed inmediately by thorough washing. Puddles that may accumulate ahout the vat during dipping should be filled with fresh earth as soon as possible and all gates to the vat corrals should be kept closed hetween dippings. When a vat is to be emptied the waste solution should be run into a pit, guarded hy a fence, where it will seep away, eare being taken to see that the seepage can not reach a water supply.

When dipping is begun in the spring the arsenical solution used should alwatys be freshly prepatred. 
Never use a bath carried over the winter. In preparing the bath for the first spring dipping it should not test higher than 0.14 per cent, as indicated by the field test for arsenical bath. At the following two or three dippings the strength of the solution should be increased gradually until it will give a test of about 0.18 per cent, and it should be held to a test of between 0.18 and 0.20 per cent for the remainder of the dipping season by replenishing, or in case it becomes filthy, by complete renewal.

In systematic tick eradication it is best to begin dipping during March, for the reason that that is the beginning of the period when tick development is rapid, and the length of time they will live on the host and on the pasture is shortest. Proper dipping of all cattle in a given area at 14-day intervals, beginning in March and continuing until November, will result in complete eradication of the cattle tick.

\section{ORGANIZATION OF FORCE.}

In tick eradication it is customary to take up systematic work in units, a county usually comprising such a division, in which the work is carried on by a cooperative State, county, and Federal force working in that county. This force should consist of a supervising inspector, local inspectors, and range riders.

Supervising inspector.-The duties of the supervising inspector are to keep in close personal touch with all details of the work, to assign the local inspectors and range riders to their divisions of territory, instruct them regarding their duties, and personally supervise their work. All reports rendered by local inspectors and range riders should pass through his hands, and any irregularities, such as failure to dip, complaints, etc., should be promptly investigated and 
adjusted. He should meet cattle owner's and interested county officials frequently, keeping them advised regarding the work, progress being made, and where and how they can assist and hasten completion of the job.

Local inspector.-The local inspector is usually appointed from the district in which he is to work, and is selected because of his knowledge of local conditions and familiarity with the cattle industry. He is assigned to a district, usually 10 or 12 adjacent vats, and conducts the inspection and dipping of all cattle in that section. Upon taking up systematic work the local inspector's first duty is to make a "cattle census" in his district. In doing this he should visit each cattle owner in his territory, make a correct record of his name, address, and number of cattle. He should advise the cattle owners regarding the work about to be taken up and explain why their cooperation is essential to success. At this time each owner should be served with a dipping notice indicating the date dipping will begin and the rat at which he is to dip. It is the duty of the local inspector to keep his vats and dipping solution in proper condition, and to check and record correctly all cattle dipped by him. He is required to report his work promptly to the supervising inspector on forms furnished for that purpose.

Range rider.-A man to fill this position should be acquainted with the section in which he is to work, and should be a good rider, experienced in handling cattle. He should have legal authority to enter any premises in the performance of his duty, and be required to furnish a good saddle horse for use in the work. It is the rider's duty to assist the local inspector at the time of dipping in checking and mark- 
ing cattle, to help owners in penning their stock at the vat, and to visit those who are tardy or fail to dip, assisting them, if necessary, in getting cattle to the vat. Within a day or two following the dipping the range rider should ride thoroughly the range

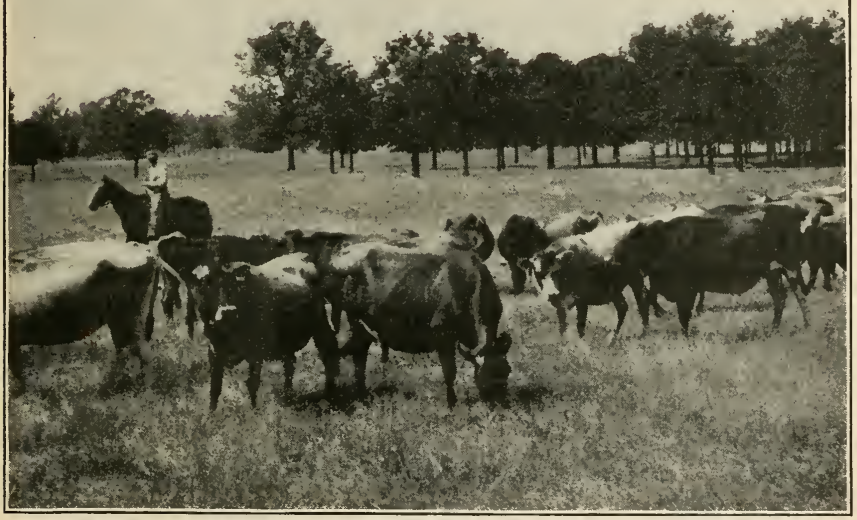

FIG. 4.-The range rider should ride the range thoroughly in search of any cattle that have not been dipped. In this search he should not confine himself to the woods and ranges, but visit barns, lots, pastures, or any other place where he may suspect that an undipped cow or calf may be, always working with the object in riew to make each dipping 100 per cent of the cattle.

tributary to that vat in search of any cattle that have not been dipped. In this search he should not confine himself to the woods and ranges, but visit barns, lots, pastures, or any other place where he may suspect that an undipped cow or calf may be, always 
working with the object in view to make each dipping 100 per cent of the cattle. Legal authority should be provided for promptly disposing of any undipped cattle found by the rider in the event that the owner fails or refuses to dip them at once. The most satisfactory manner of disposal is to authorize the dipping of the cattle at the owner's expense, the expense incurred becoming a lien on the cattle, and providing for the sale of the cattle to cover the costs, if not promptly paid by the owner.

\section{PAINT-MARK ('HECK.}

To dip only a part of the cattle on a range or in an infested community delays completion of the work indefinitely. It is, therefore, of the greatest importance that a system of checking dipped cattle for identification be adopted.

The paint-mark method of checking dipped cattle is of great assistance in insuring the disinfection of all cattle in large, rough pastures and open ranges and should be provided for in all regulations governing tick eradication.

In using this check, the mark should be placed uniformly each time it is used, changing the location as necessary. For example, the mark at the first dipping may be placed on the left shoulder, the second on the left side, and the third on the left hip. Sheepbranding fluid or ink, which ean be ordered from any paint dealer, will be found a cheap and satisfactory material for this use if procured in a distinctive color, such as bright red or bright green. Best results will be obtained by applying the paint mark on the dry hair as the cattle enter the vat. It is not necessary to smear the paint over a large surface; a circular spot 3 or 4 inches in diameter can be distinguished at 
a considerable distance and with a little practice the range rider can accurately identify cattle that have not been dipped and marked.

\section{RECORDS.}

The importance of complete and correct field records in systematic tick eradication can not be too strongly emphasized. Without such records it is practically impossible to conduct the work properly during the dipping season; and at the close of the season, if reliable records are not available, the tick status of the herds and ranges can not be determined, and the question of release from quarantine is problematical.

The best and simplest method of keeping these records is by use of the card-record system devised by the Bureau of Animal Industry, using the form known as Tick Form 48-G. This card is so arranged that it furnishes all necessary information with a minimum of clerical work.

The local inspector should make a $48-\mathrm{G}$ card record for each herd in his territory. These individual cards should be taken to the vat at every dipping and proper entry made on each owner's card as soon as his cattle are inspected and dipped. The supervising inspector should examine these records at frequent intervals to see that they are correctly kept. In additional to the individual 48-G record, one card, giving the total number of herds and cattle, should be kept for each vat. This vat record should be made in duplicate, one being kept by the local inspector in conjunction with his individual record, the other by the supervising inspector, who will make the entries on his card from the daily dipping reports rendered by the local inspector. 
RELEASE OF AREAS FROM QUARANTINE.

At the close of the season's work, usually December 1 , the question must be decided whether or not the area in which systematic tick eradication has been conducted is in condition for release from State and Federal quarantine, and a correct decision can he reached only by carefully studying the records covering the season's work, and giving due consideration

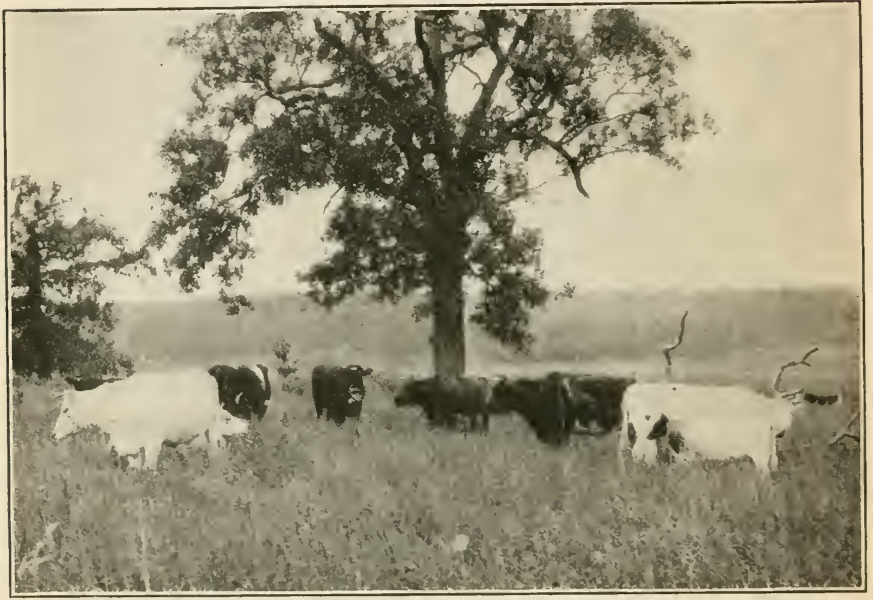

FIG. 5.-The large area that has been freed and remains tiek-free is making possible the establishment of a growing and profitable eattle industry in the South.

to local conditions that will affect the final clean-up in that area. A county that has expended its funds in this work, and inclividual cattle owners who have cooperated faithfully and have eliminated the tick from their premises are entitled to the benefits that follow release from State and Federal quarantine, and should receive this relief just as soon as it can be given with safety. 
As a general rule it is not advisable to release an area that comprises less than a county. If the ideal has been attained and the work carried out 100 per cent perfect, ticks will be eradicated at the end of the season and the county will be in perfect condition for release. However, as this ideal condition is the exception rather than the rule, it is usually necessary to decide whether or not, in the event of release from quarantine, the infestation that remains may be controlled without danger to the released area. With a correct $48-\mathrm{G}$ card record, the exact status, as regards tick infestation, may be easily determined, the pastures or ranges that will probably show infestation during the following season may be definitely located, and the question of exposure to adjoining free area determined. If all cattle in the county are held under fence, that county may be safely released from quarantine even if a considerable number, up to 1 per cent, of the herds have to be held under local or farm quarantine to complete eradication. However, such release should be made only with the distinct understanding and agreement on the part of State and county officials that the infested herds will be held under strict quarantine and that the eradication work on these premises will proceed without interruption until completed.

The final work of eradicating ticks in infested herds remaining under local quarantine requires careful attention, and this work should always be assigned to an experienced inspector, who is required to inspect and supervise personally the dipping of all cattle remaining under quarantine. Because ticks were "nearly" eradicated at the close of the season, it is not safe to depend upon inspections to determine the freedom of the herd. Regular dipping 
should be insisted upon until sufficient time has elapsed since ticks were last found to insure eradication. "When in doubt dip" is a good rule to follow in final work.

In "open" or "free" range counties the matter of release from quarantine while infestation remains in the county requires careful consideration of local conditions, and unless the infested area is small and separated from the tick-free area by a natural barrier, such as a river, the county should not be released from quarantine until tick eradication is completed. Under open-range conditions, where one careless owner by neglecting to disinfect properly one cow may expose a range used by 100 other herds and thereby place all herds in the same status as his, tick eradication more than ever is a community problem which will be disposed of only when the community as a whole completes tick eradication.

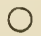


Systematic

Dipping in an

\section{Arsenical Solution}

Is the method most followed in tick eradication. Occasionally, however, it is feasible to employ the "Starvation" or "PastureResting" method in eliminating the tick from a pasture.

Proper dipping of all cattle at 14-day intervals, beginning in March and continuing until November,

\section{Will Lead to Final \\ Eradication of Cattle Ticks.}


THIS BOOK IS DUE ON THE LAST DATE STAMPED BELOW

AN INITIAL FINE OF 25 CENTS WILL BE ASSESSED FOR FAILURE TO RETURN THIS BOOK ON THE DATE DUE. THE PENALTY WILL INCREASE TO 50 CENTS ON THE FOURTH DAY AND TO \$1.00 ON THE SEVENTH DAY OVERDUE.

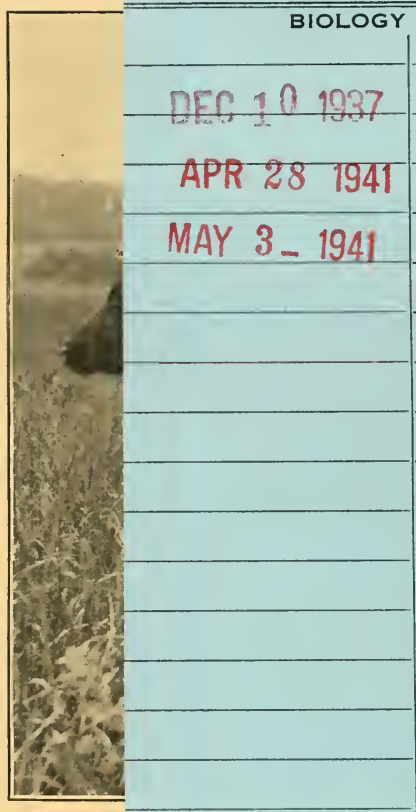

Tick-free II,

\section{LIBRARY}
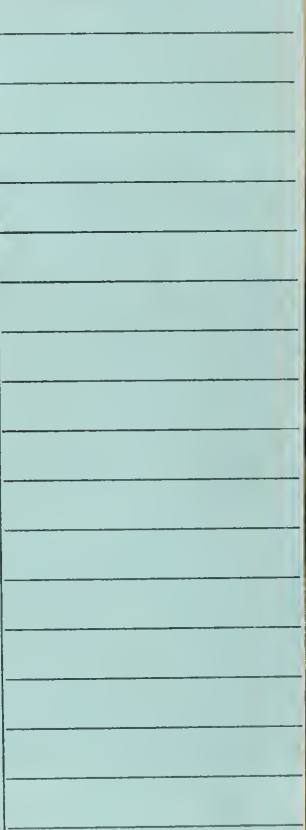

as the Result

LD $21-5 m \cdot 7 ; 37$ 


\section{7\%}

Tisi

Li 3 RAT:

G

UNIVERSITY OF CALIFORNIA LIBRARY 
